\title{
Exploring the metallochromic behavior of pentacyanidoferrates in visual, electronic and Raman spot tests
}

\author{
JORGE S. SHINOHARA, DANIEL GRASSESCHI, SABRINA N. ALMEIDA and HENRIQUE E. TOMA \\ Instituto de Química, Universidade de São Paulo, Av. Prof. Lineu Prestes, 748, 05508-000 São Paulo, SP, Brazil
}

Manuscript received on March 26, 2018; accepted for publication on June 20, 2018

\begin{abstract}
How to cite: SHINOHARA JS, GRASSESCHI D, ALMEIDA SN AND TOMA HE. 2019. Exploring the metallochromic behavior of pentacyanidoferrates in visual, electronic and Raman spot tests. An Acad Bras Cienc 91: e20180315. DOI 10.1590/0001-3765201920180315.

Abstract: Pentacyanidoferrate(II) complexes of aromatic N-heterocycles, such as 4-cyanopyridine, exhibit characteristic colors and strong metallochromism associated with the donor-acceptor interactions of the metal ions with the cyanide ligands. In the presence of transition metal ions insoluble polymeric complexes are formed, displaying bright yellow, red, brown and green colors with zinc(II), nickel(II), copper(II) and iron(III) ions, respectively. Such metallochromic response is better observed on filter paper, allowing applications in analytical spot tests. The effects can be explored visually and probed by means of modern instrumental facilities, including spectrophotometric and resonance Raman techniques. In this way, by using the cyanopyridinepentacyanidoferrates, the Prussian Blue test for ferric ions can be extended to the entire row of transition metal elements, providing a new and modern insight of such classical Feigl's spot tests.
\end{abstract}

Key words: pentacyanidoferrates, Feigl spot tests, Prussian blue, resonance Raman, ring oven.

\section{INTRODUCTION}

Colorimetric reagents have been extensively explored in analytical chemistry since the beginning of the last century, after the outstanding work of Fritz Feigl on spot tests (Feigl and Anger 972). Because of their simple use, spot tests became a common practice in Chemistry and Forensics, allowing rapid and practical detection of analytes, including representative, lanthanide and transition metal ions. They are usually performed using spot test plates or filter paper, allowing many interesting variations, for instance, by combining solvent elution and rapid evaporation procedures as in the

Correspondence to: Henrique Eisi Toma

E-mail: henetoma@iq.usp.br

ORCid: orcid.org/0000-0002-4044-391X so called "ring oven" technique (Riyazuddin 1994, Cortez and Pasquini 2013). Such strategy allows to concentrate the analytes on a paper spot, increasing the sensitivity of the analysis.

On the other hand, the limits of the visual detection of the spot tests can also be extended with the aid of modern instrumental facilities, encompassing for instance, fiber optics spectrophotometry and Raman techniques. Such instrumental detection can be directly applied on spot test plates and filter paper, providing more than just a positive or negative response, allowing to access the chemical nature of the analytes by means of their electronic and vibrational features.

A good example has already been reported in a confocal Raman study of the Feigl spot test 
for palladium(II) in the presence of nickel(II) ions, using the dimethylglyoxime $(\mathrm{dmgH})$ reagent (Huila et al. 2012). This spot test was based on the sensitivity of the nickel complex to acids due to the protonation of the $\mathrm{dmgH}$ ligand, breaking the macrocyclic structure and leading to the loss of the characteristic red color associated with the square planar configuration of the $\left[\mathrm{Ni}(\mathrm{dmgH})_{2}\right]$ complex. On the other hand, palladium(II) ions also react with dimethylglyoxime, yielding a very stable, planar, yellow $\left[\mathrm{Pd}(\mathrm{dmgH})_{2}\right]$ complex, which is resistant to acids. Feigl (Feigl 1943) proposed that the presence of palladium(II) ions preserves the red color of the nickel(II) complex from the attack of acids, by forming a protective coating. However, we have shown that the bis(dimethylglyoximate) nickel(II) complex is actually formed by stacking interactions, generating deep red microscopic needles which can be readily observed on the cellulose fibers. This observation indicated that the most accessible sites for protonation are located at the needles end, where the complex is completely exposed. When palladium ions are present in the mixture, they can block the acid attack on the nickel(II) complex by protecting the needle extremities, thus preserving the red color. All these aspects have been clearly demonstrated by confocal Raman spectroscopy, providing a completely new insight on such classical Feigl spot test.

Another interesting case is the classical Prussian blue test, which has been routinely performed for $\mathrm{Fe}$ (III) ions, since its discovery in 1704. The Prussian blue complex is composed by $\mathrm{Fe}(\mathrm{II})$ and $\mathrm{Fe}(\mathrm{III})$ ions bridged by cyanide ligands and has been denoted a "mixed-valence" complex, after Robin (Robin 1961) and Day (Robin and Day 1967). Prussian blue is prototype of a class of compounds exhibiting metal-to-metal, or "intervalence" (IT) transitions. Intervalence transfer bands were extensively investigated in the 1970 - 1980 decades, especially by Taube and coworkers (Ford et al. 1968, Creutz and Taube
1973), establishing important parallelisms between optical and thermal electron transfer. In this area, the related chemistry of pentacyanidoferrate(II)/ (III) complexes also exhibited a great boom in the 1970-1990 decades (Toma et al. 1973, 1982, Toma and Creutz 1977, Toma and Malin 1973), because of their rich electronic and intervalence properties.

In this paper we are expanding the spot tests inspired on Prussian Blue chemistry, replacing a cyanide ligand by the 4-cyanopyridine (pyCN) molecule. It has been shown (Toma et al. 1987) that the pyCN ligand forms a strong bond with the $(\mathrm{CN})_{5} \mathrm{Fe}(\mathrm{II})$ moiety by coordinating at the N-pyridine atom, yielding a deep red-orange complex displaying a strong $\mathrm{Fe}(\mathrm{II})$-to-pyCN $\left(\mathrm{d}_{\pi} \rightarrow \mathrm{p}_{\pi}{ }^{*}\right)$ chargetransfer transition. In this way, the pyCN ligand is important for introducing a new chromophore group in the complex, allowing to sense the chemical interactions with transition metal ions. In contrast to the $\left[\mathrm{Fe}^{\mathrm{II}}(\mathrm{CN})_{6}\right]^{4-}$ complex, the $\left[\mathrm{Fe}^{\mathrm{II}}(\mathrm{CN})_{5}(\mathrm{pyCN})\right]^{3-}$ species form strongly colored complexes with all the transition metal ions in aqueous solution; however, their application on spot tests has never been published before. As an improvement, the use of the ring oven technique was also explored in this work, in order to enhance the colors and improve the detection limit, in association with electronic and resonance Raman spectroscopy.

\section{MATERIALS AND METHODS}

$\mathrm{Na}_{3}\left[\mathrm{Fe}(\mathrm{CN})_{5} \mathrm{NH}_{3}\right] .3 \mathrm{H}_{2} \mathrm{O}$ was synthesized by reacting $\mathrm{Na}_{2}\left[\mathrm{Fe}(\mathrm{CN})_{5} \mathrm{NO}\right] \cdot 2 \mathrm{H}_{2} \mathrm{O}$ with ammonia, as described in the literature (Toma and Malin 1973, Toma et al.1982). 4-cyanopyridine (pyCN), $\mathrm{FeSO}_{4} .7 \mathrm{H}_{2} \mathrm{O}, \mathrm{CuSO} .5 \mathrm{H}_{2} \mathrm{O}, \mathrm{CoSO}_{4} .7 \mathrm{H}_{2} \mathrm{O}$, $\mathrm{MnSO}_{4} 7 \mathrm{H}_{2} \mathrm{O}, \mathrm{ZnSO}_{4} .7 \mathrm{H}_{2} \mathrm{O}, \mathrm{NiSO}_{4} \cdot 7 \mathrm{H}_{2} \mathrm{O}$, are commercially available (Sigma-Aldrich, Merck) as analytical grade reagents and were used as supplied. The $\left[\mathrm{Fe}(\mathrm{CN})_{5}(\text { pyCN })\right]^{3-}$ complex was prepared by dissolving $\mathrm{Na}_{3}\left[\mathrm{Fe}(\mathrm{CN})_{5} \mathrm{NH}_{3}\right] \cdot 3 \mathrm{H}_{2} \mathrm{O}$ in an aqueous solution of pyCN $(20 \mathrm{mM})$ in order 
to yield a $10 \mathrm{mM}$ stock solution. An excess of pyCN has been employed to ensure the complete substitution of the $\mathrm{NH}_{3}$ ligand from the starting aminopentacyanidoferrate(II) complex (Toma and Malin 1973).

Whatman chromatography paper was employed for the spot test analysis, but conventional filter papers can also be used for routine or qualitative purposes. The metal ions $\left(10 \mathrm{mmol} \mathrm{L}^{-1}\right)$ were deposited on the paper using a micrometric syringe. After applying the pentacyanidoferrate reagent, the paper was copiously washed with water and allowed to dry at room temperature. In the case of the $\mathrm{Fe}^{2+}$ test, an equivalent amount of ascorbic acid was also added before the reaction with the pentacyanidoferrate complex, in order to postpone the air oxidation of the complex. Nevertheless, the paper was kept under a flow of nitrogen, and for long term experiments it should be stored in the absence of air.

Instead of the classical ring oven technique, the samples were applied by depositing on the filter paper, successive amounts $(50 \mathrm{~nL})$ of the metal ion solutions, using a chromatographic syringe. The paper was previously placed on a metal ring over a heating plate, keeping a constant temperature (e. g., $70{ }^{\circ} \mathrm{C}$ ) in order to control the evaporation rate and the spot size.

Optical reflectance spectra of the filter paper spots were recorded on a fiber optics Specfield spectrophotometer, in the $350-1600 \mathrm{~nm}$ region. The corresponding Raman spectra were obtained using an Alpha 300R WITec confocal Raman microscope, at 488 and 532 excitation wavelengths, by applying a minimum laser power in association with a high sensitive EMS detector, in order to minimize the spot damage.

\section{RESULTS AND DISCUSSION}

\section{VISUAL SPOT TESTS}

One of the most intriguing aspects observed in this work is the remarkable color changes produced by the $\left[\mathrm{Fe}(\mathrm{CN})_{5} \text { pyCN }\right]^{3-}$ complex when applied to the spot test analysis of transition metal ions, as shown in Fig. 1.

The reactions carried out on the filter paper proceed according to equation (1), yielding insoluble Prussian blue like complexes of general composition $\mathrm{M}_{\mathrm{x}}[\mathrm{FeCN})_{5} \mathrm{pyCN}_{\mathrm{y}}$, displaying red $\left(\mathrm{Mn}^{2+}\right)$, brick-red $\left(\mathrm{Co}^{2+}\right)$, red-violet $\left(\mathrm{Ni}^{2+}\right)$, dark magenta $\left(\mathrm{Fe}^{2+}\right)$, brown $\left(\mathrm{Cu}^{2+}\right)$, green $\left(\mathrm{Fe}^{3+}\right)$ and bright yellow $\left(\mathrm{Zn}^{2+}\right)$ colors.

$$
\mathrm{xM}^{\mathrm{n}+}+\mathrm{y}\left[\mathrm{Fe}(\mathrm{CN})_{5} \mathrm{pyCN}^{3-} \rightarrow \mathrm{M}_{\mathrm{x}}[\mathrm{FeCN})_{5} \mathrm{pyCN}_{\mathrm{y}}(1)\right.
$$

The spot tests can be performed by applying the $\left[\mathrm{Fe}(\mathrm{CN})_{5} \text { pyCN }\right]^{3-}$ complex on the paper containing the elements, and the final colors revealed after washing copiously with water. Such colors are very stable, and some curious amateur paints have been made to illustrate the spot test design on filter paper, as shown in Fig. 2. Such paints were performed by applying diluted solutions of the several metal

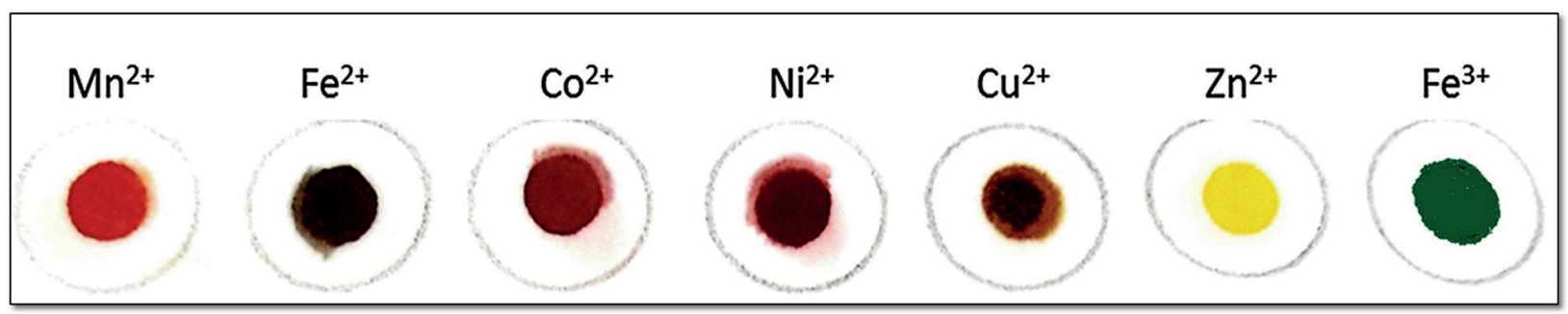

Figure 1 - Metallochromic response of the $\left[\mathrm{Fe}(\mathrm{CN})_{5} \text { pyCN }\right]^{3-}$ complex applied on filter paper containing the metal ions (bright yellow $=\mathrm{Zn}^{2+}$, red $=\mathrm{Mn}^{2+}$, brick-red $=\mathrm{Co}^{2+}$, red-violet $=\mathrm{Ni}^{2+}$, dark magenta $=\mathrm{Fe}^{2+}$, brown $=\mathrm{Cu}^{2+}$, green $=\mathrm{Fe}^{3+}$ ), after washing with water. 


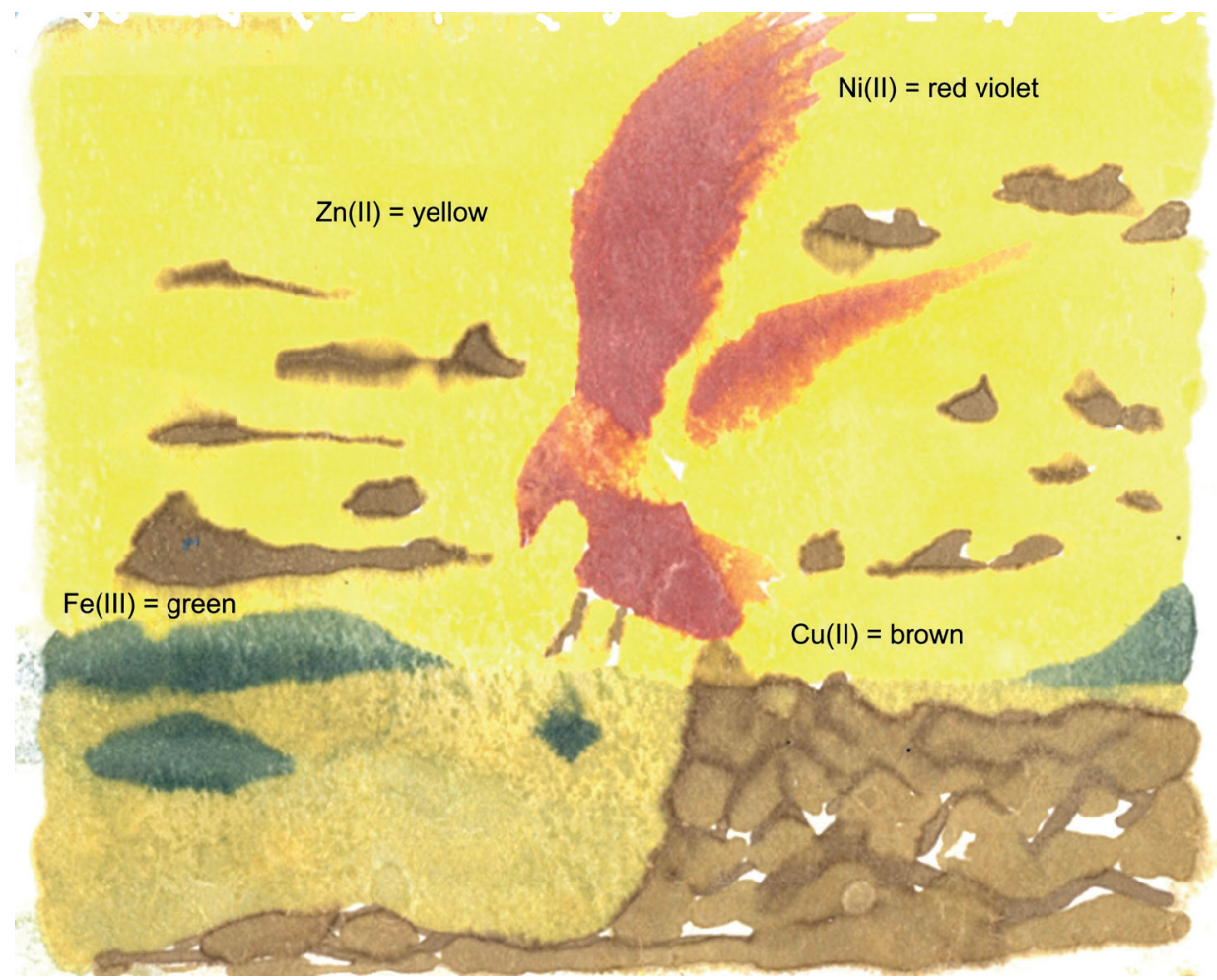

Figure 2 - Decorative spot test paint with $\left[\mathrm{Fe}(\mathrm{CN})_{5} \mathrm{pyCN}\right]^{3-}$ applied to transition metal ions on filter paper.

ions, with a paintbrush, and allowing to dry. The colors revealed on the white paper, after applying the $\left[\mathrm{Fe}(\mathrm{CN})_{5} \mathrm{pyCN}\right]^{3-}$ reagent, resemble a typical performance with magic ink, e. g. in classroom demonstrations.

The substitution of a cyanide ligand in the $\left[\mathrm{Fe}(\mathrm{CN})_{6}\right]^{4-}$ complex introduces a new Fe $\mathrm{Fi}^{\mathrm{II}}-\mathrm{pyCN}$ chromophore group displaying a strong metalligand charge-transfer transition at $480 \mathrm{~nm}$. However, the colors of the pentacyanidoferrates are quite unusual because of the presence of the five cyanide ligands which can interact with the surrounding species, such as the solvent molecules, leading to strong solvatochromic effects (Toma and Takasugi 1983, 1989), or with transition metal ions, producing unusual metallochromic effects.

The binding of the metal ions to the cyanide ligands in the $\left[\mathrm{Fe}(\mathrm{CN})_{6}\right]^{4-}$ complex has been well characterized in the Prussian blue complex (Ludi et al.1969), exhibiting the $\mathrm{Fe}_{4}\left[\mathrm{Fe}(\mathrm{CN})_{6}\right]_{3}$ composition with a (low spin)Fe $\mathrm{Fe}^{\mathrm{II}}-\mathrm{CN}-\mathrm{Fe}^{\mathrm{III}}$ (high spin) configuration. The cyanide ligands form extended bridged cubic structures, generating internal vacancies for accomodating solvent molecules and eventually, alkaline ions such as $\mathrm{Cs}^{+}$. For this reason, it was already employed in the treatment of radioactive $\mathrm{Cs}^{+}$contamination (Dechojarassri et al. 2017) in the terrible nuclear tragedies occurred in 1987 in Goiania city (Brazil), and in 2011, in Fukushima (Japan)(Parajuli et al. 2016).

In the case of the $\left[\mathrm{Fe}(\mathrm{CN})_{5} \text { pyCN }\right]^{3-}$ analogue, in addition to the extended bridged structures promoted by the five cyanide ligands, a new chromophore group, Fe-pyCN is introduced, exhibiting a characteristic $\mathrm{Fe}(\mathrm{II}) \rightarrow$ pyCN chargetransfer band at $480 \mathrm{~nm}$.

The visual detection limit in the spot test analysis depends upon the sample distribution on the filter paper, and also on the molar absorptivity of the colorimetric reagent employed. Although 
the optical absorption is not particularly large for the pentacyanidoferrates $\left(\varepsilon=10^{3}-10^{4} \mathrm{~mol} \mathrm{~L}^{-1}\right.$ $\mathrm{cm}^{-1}$ (Toma and Malin 1973)), the formation of insoluble complexes on the cellulose fibers improves the contrast and the visual detection, yielding a positive response even at very diluted conditions, e. g. $10^{-5} \mathrm{~mol} \mathrm{~L}^{-1}(\sim 1 \mathrm{ppm})$. The detection limit can be further improved by using the ring oven technique illustrated in Fig. 3. The technique consists in applying the sample on a filter paper and evaporating, sequentially, in order the concentrate the analyte on the spot, proportionally to the number of repetition steps. In this case, the use of chromatography syringes allows to precisely controlling the concentration and spot size. In this way, it is possible to enhance the color and to extend the visual detection below the ppm range.

\section{ELECTRONIC DETECTION OF THE SPOT TESTS} AND CHARACTERIZATION OF THE SPECTRAL BANDS

The electronic spectra recorded for the several spot tests shown in Figure 1, can be seen in Fig. 4. A fiber optics spectrophotometer has been employed, allowing in situ measurements for discriminating the electronic bands in the spots.

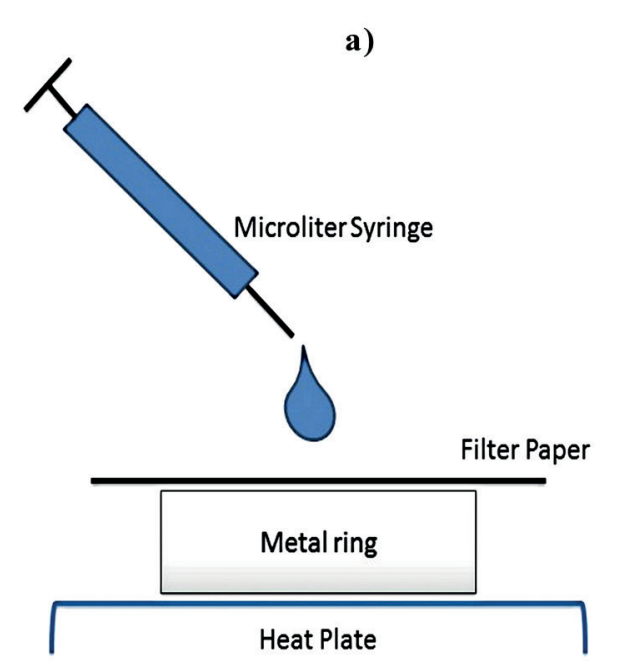

The $\left[\mathrm{Fe}(\mathrm{CN})_{5}(\mathrm{pyCN})\right]^{3-}$ chromophore is really strategic since it allows to probe the interaction of the complex with metal ions, through the perturbation of the $\mathrm{Fe}^{\mathrm{II}} \mathrm{d}_{\pi}$ orbitals via metalation of the isocyanide and pyCN ligands. A didactic diagram can be seen in Fig. 5, showing how the interaction of the metal ions with the isocyanide and pyCN groups perturbs the electronic levels of the $\left[\mathrm{Fe}(\mathrm{CN})_{5}(\mathrm{pyCN})\right]$ core.

Accordingly, the hypsochromic shift of the $\mathrm{Fe} \rightarrow$ pyCN MLCT band observed in the case of the $\mathrm{Zn}^{2+}$ ions is consistent with the electron withdrawing effects after their N-binding to the cyanide ligands, enhancing the backbonding interactions with the low spin $\mathrm{Fe}$ (II) center. The consequent stabilization of the $\mathrm{Fe}(\mathrm{II}) \mathrm{d}_{\pi}$ orbitals (Fig. 5b) promotes a hypsochromic shift of the MLCT band, explaing the bright yellow color of the $\mathrm{Zn}^{2+}$ complex.

In the case of the $\mathrm{Ni}^{2+}$ ions, a bathochromic shift of the MLCT band is observed, and such effect is presumably related to their smaller electron withdrawing influence on the cyanide ligands, as compared with the $\mathrm{Zn}^{2+}$ ions. In this way, the major changes should be associated with the stabilization of the pyCN ligand orbitals, as illustrated in Fig. 5c.

The remaining metal ions show an intermediate behavior in relation to the $\mathrm{Zn}^{2+}$ and $\mathrm{Ni}^{2+}$ ions.

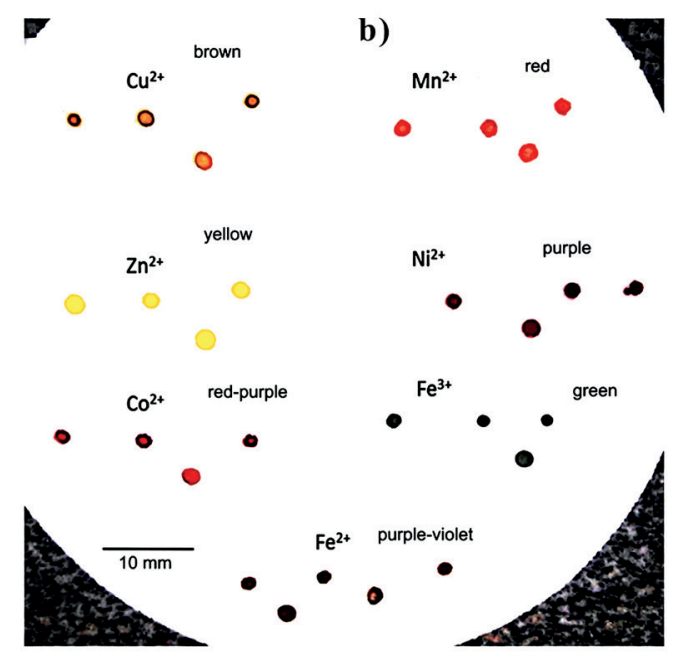

Figure 3 - Improving the detection limit by means of the ring oven technique (a), with the sample concentrated on a single spot after repetitive applications (b). 


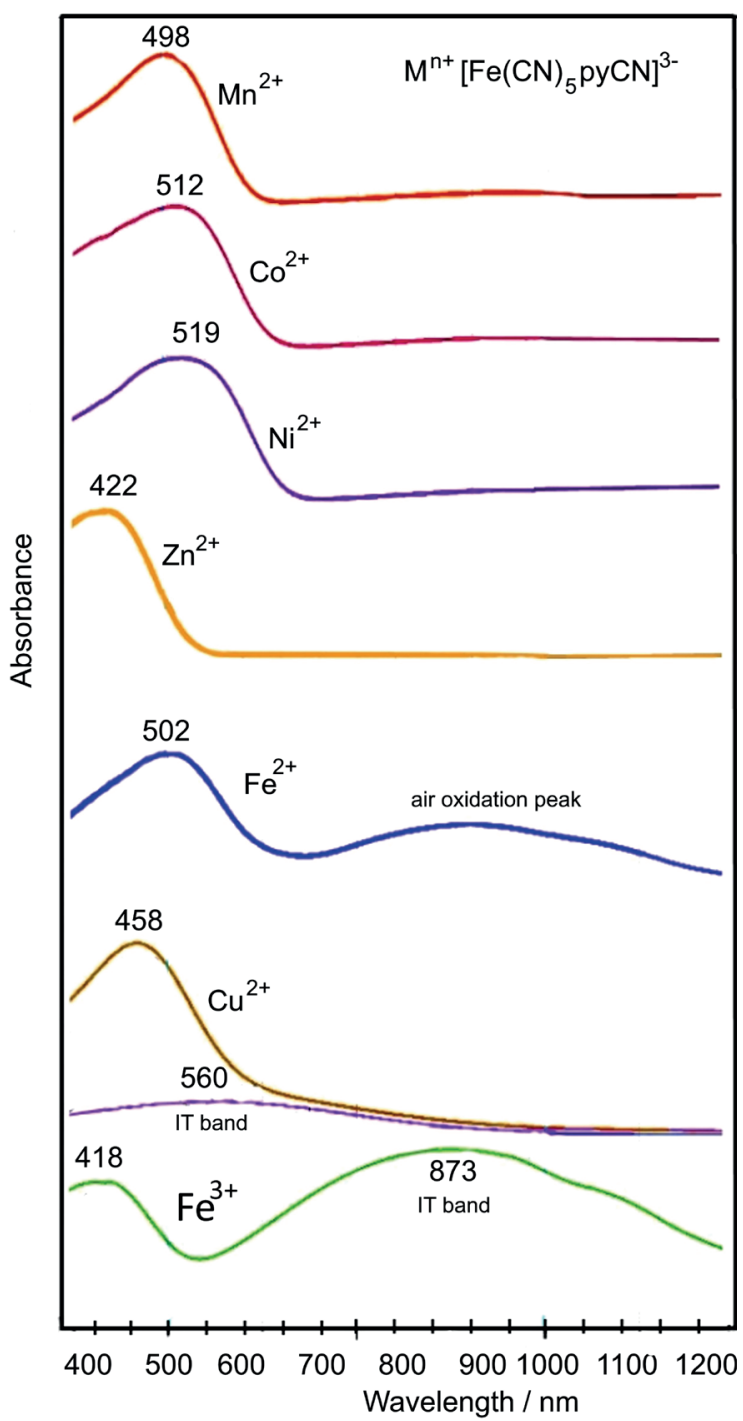

Figure 4 - Fiber-optics reflectance spectra of $\mathrm{M}_{\mathrm{x}}\left[\mathrm{Fe}(\mathrm{CN})_{5}(\text { pyCN })\right]_{\mathrm{y}}$ generated directly on the filter paper spots

In the case of $\mathrm{Cu}^{2+}$ and $\mathrm{Fe}^{3+}$ ions, a new band is observed in the electronic spectra, corresponding to intervalence transfer (IT) transitions, also observed in the related Prussian blue complexes. Such IT bands can be explained by the molecular orbital scheme in Fig. 6.

In the case of the $\mathrm{Cu}^{2+}$ complex, an IT band can be located at $560 \mathrm{~nm}$, as a shoulder in the corresponding MLCT band in the visible. This band is weak, since it involves a symmetry forbidden $\mathrm{Fe}\left(\mathrm{d}_{\pi}\right) \rightarrow \mathrm{Cu}\left(\mathrm{d}_{\sigma}\right)$ transition (Toma 1976). In the case of the $\mathrm{Fe}^{3+}$ complex, a symmetry allowed $\mathrm{Fe}^{\mathrm{II}}\left(\mathrm{d}_{\pi}\right) \rightarrow \mathrm{Fe}^{\mathrm{III}}(\mathrm{d} \pi)$ transition is observed at $873 \mathrm{~nm}$, generating a deep green color, while the expected $\mathrm{Fe}^{\mathrm{II}}\left(\mathrm{d}_{\pi}\right) \rightarrow \mathrm{Fe}^{\mathrm{III}}\left(\mathrm{d}_{\sigma}\right)$ symmetry forbidden transition is masked by the MLCT band around $418 \mathrm{~nm}$.

\section{RESONANCE RAMAN MONITORING OF THE SPOT TESTS}

In order to improve the analysis, the resonance Raman technique has also been applied to the spot tests. All the metal ions exhibited strong resonance Raman enhancement on the filter paper, leading to very similar spectra associated with the $\mathrm{Fe}^{\mathrm{II}}(\mathrm{CN})_{5}$ and pyCN moieties interacting with the transition metal ions, as shown in Fig. 7.

The resonance Raman spectra exhibited characteristic peaks in the $2235-2245 \mathrm{~cm}^{-1}$ interval, associated with the $v(\mathrm{CN})$ stretching vibration of the coordinated pyCN ligand. Other typical peaks occur at $2140-2145 \mathrm{~cm}^{-1}$ corresponding to the $v_{\mathrm{a} 1}(\mathrm{CN})$ vibrations of the $\left[\mathrm{Fe}^{\mathrm{II}}(\mathrm{CN})_{5}\right]^{3-}$ group (Griffith and Turner 1970). The major peak is accompanied by a weak shoulder around 2060$2080 \mathrm{~cm}^{-1}$ corresponding to a Raman inactive $v(\mathrm{CN})$ vibration. The $v(\mathrm{CN})$ stretching vibrations of the $\left[\mathrm{Fe}^{\mathrm{II}}(\mathrm{CN})_{5}\right]^{3-}$ groups exhibit a general increase in the vibrational frequencies from $\mathrm{Mn}^{2+}$ to $\mathrm{Zn}^{2+}$ ions (Fig. 8), reflecting with the local electron withdrawing effects exerted by the metal ions.

In addition to the $v(\mathrm{CN})$ bands, the Raman spectra exhibited sharp peaks around 1600, 1240, $1210,1020 \mathrm{~cm}^{-1}$ corresponding to the $v(\mathrm{C}-\mathrm{C}), \mathrm{v}(\mathrm{X}-$ sens), $\beta(\mathrm{CH})$, and $v$ (ring) vibrations of the pyCN ligand, as well as, less intense peaks around 580 and $500 \mathrm{~cm}^{-1}$ associated with $\delta(\mathrm{FeCN})$ and $v(\mathrm{X}-$ sens) vibrations. The (X-sens) notation refers to vibrational peaks of the py-X ligand which are very sensitive to the nature of the $\mathrm{X}$ group (Greeen and Harrison 1977).

In this way, within the spectral error interval $\left( \pm 2 \mathrm{~cm}^{-1}\right)$, vibrational peaks at 2248, 2155 and $1025 \mathrm{~cm}^{-1}$ would be characteristic of $\mathrm{Zn}^{2+}$, while vibrational peaks at 2242, 2144 and $1018 \mathrm{~cm}^{-1}$ would 


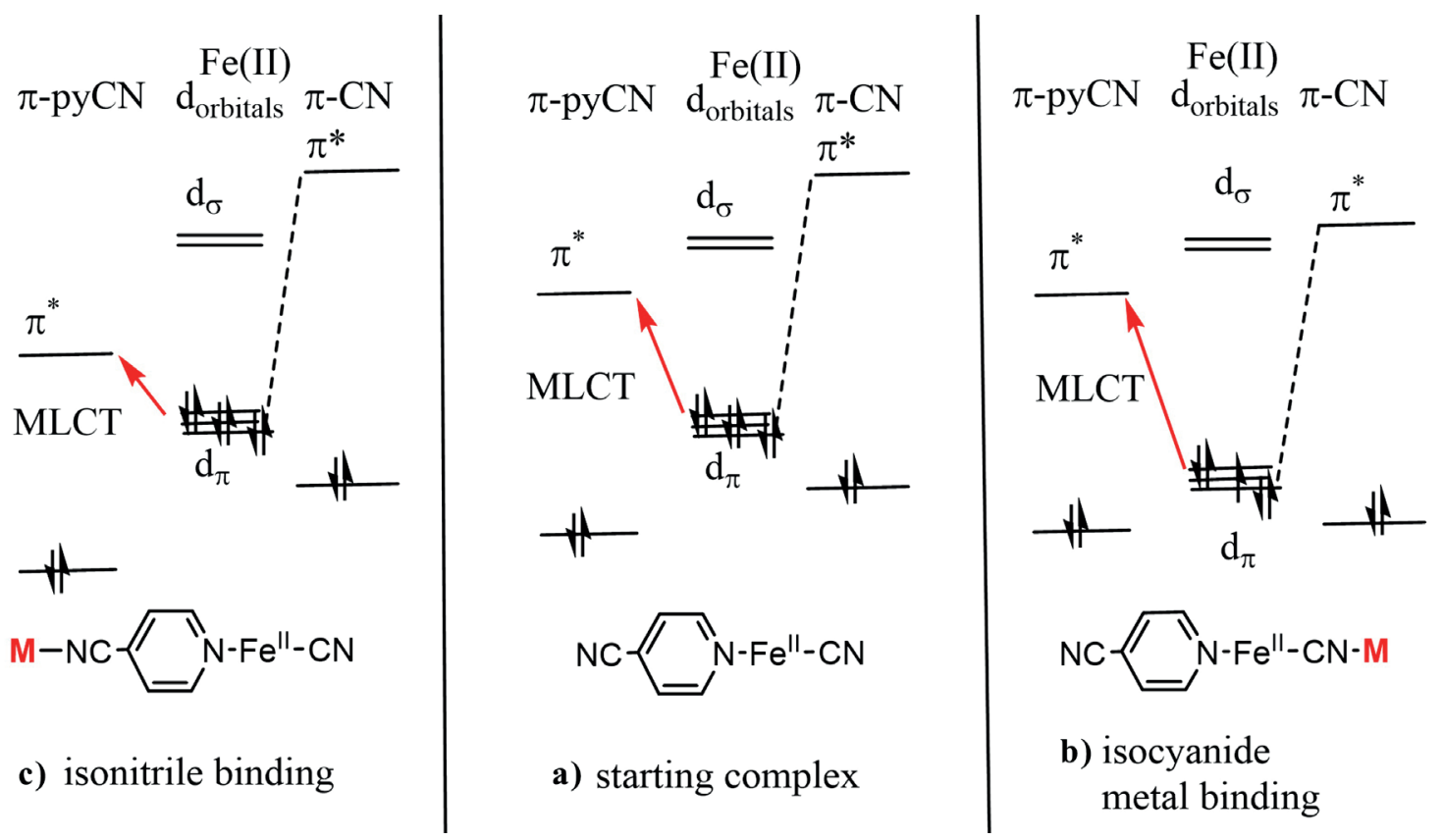

Figure 5 - (a) In the center, it is shown the orbital diagram of the $\left.\left[\mathrm{Fe}(\mathrm{CN})_{5}\right)(\mathrm{pyCN})\right]^{3-}$ complex; (b) the binding of the metal ions to the cyanide ligand enhances the backbonding interaction from the iron(II) core, stabilizing the $\mathrm{Fe}$ (II) $\mathrm{d}_{\pi}$ orbitals and increasing the Fe-to-pyCN charge-transfer energy; (c) the binding of the metal ions to the pyCN ligand improves its $\pi$-acceptor properties, decreasing the energy of the corresponding MLCT band.

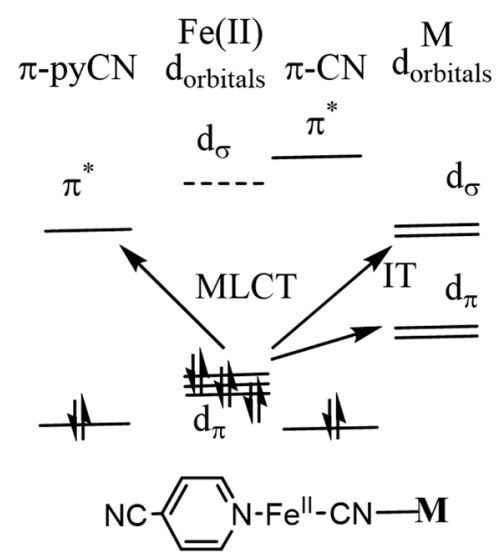

Figure 6 - Molecular orbital diagram illustrating the metal-toligand charge-transfer transition (MLCT) and the intervalence transfer transitions (IT).

correspond to $\mathrm{Ni}^{2+}$, and at 2240, 2118 and $1020 \mathrm{~cm}^{-1}$ would be indicative of $\mathrm{Mn}^{2+}$. It is also possible to monitor the samples using two different lasers, e.g. at 488 and $532 \mathrm{~nm}$, in order to discriminate the relative resonance Raman enhancement factors associated with each specific chromophore. This procedure, however, is more elaborated and requires a careful design for obtaining comparative results.
Finally, it should be mentioned that the confocal Raman microscopy allows to monitor the spot tests directly on the cellulose fibers, at a microscopic level, generating a visual metal ion distribution by means of their hyperspectral image, as illustrated for the $\mathrm{Ni}^{2+}$ ions in Fig. 9. In this case, the image generated from the Raman spectra of the $\mathrm{Ni}_{3}\left[\mathrm{Fe}(\mathrm{CN})_{5} \text { pyCN }\right]_{2}$ complex (Fig. 9b) reveals a homogeneous distribution of the complex over the cellulose fibers, practically reproducing the original optical image shown in Fig. 9a. A further gain of sensitivity can also be obtained using confocal Raman techniques, by accessing the microscopic domains of the spot tests.

\section{CONCLUSIONS}

By exploring the metallochromic effects, the $\left[\mathrm{Fe}(\mathrm{CN})_{5} \mathrm{pyCN}^{3-}\right.$ complex can be suitably employed in spot test analysis for transition metal ions, displaying remarkable color changes and resonance Raman signals. In special, the bright yellow color 


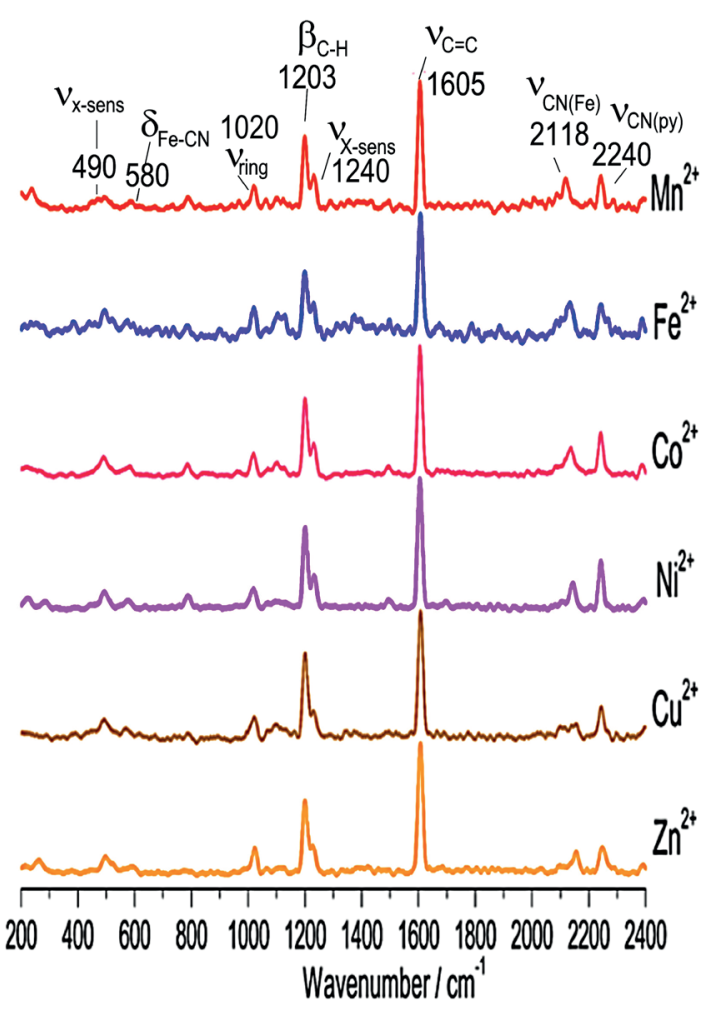

Figure 7 - Resonance Raman spectra of the $\mathrm{M}_{\mathrm{x}}\left[\mathrm{Fe}(\mathrm{CN})_{5}(\mathrm{pyCN})\right]_{\mathrm{y}}$ complexes on the filter paper spots containing $\mathrm{Mn}^{2+}, \mathrm{Fe}^{2+}, \mathrm{Co}^{2+}, \mathrm{Ni}^{2+}, \mathrm{Cu}^{2+}$ and $\mathrm{Zn}^{2+}$ ions.

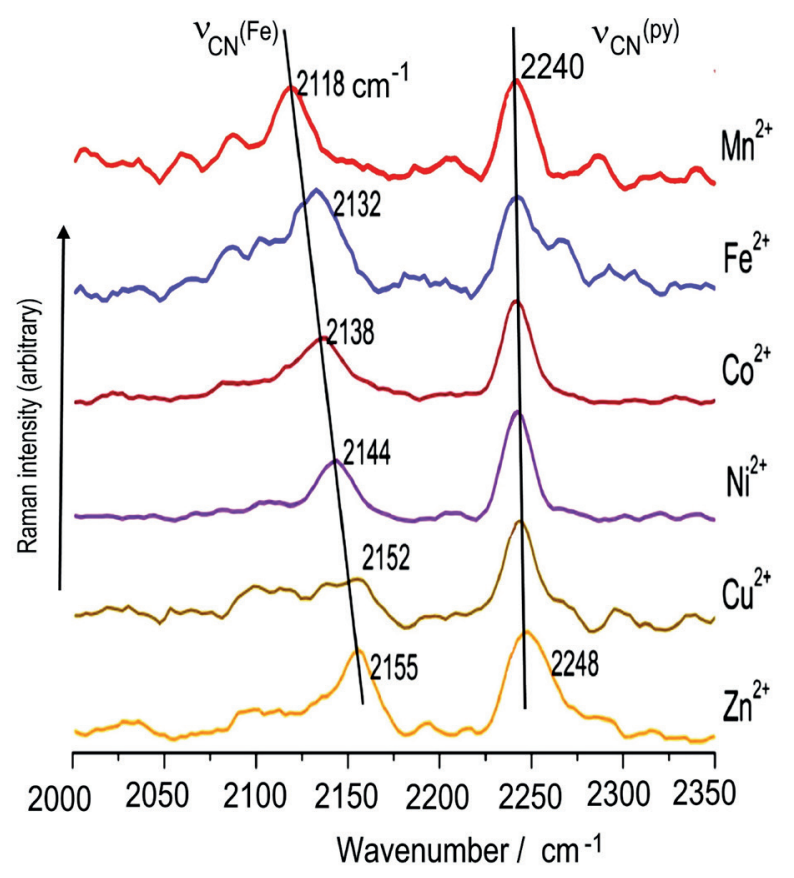

Figure 8 - Variation of the $\mathrm{M}-\mathrm{N} \equiv \mathrm{C}-\mathrm{Fe}(\mathrm{II})$ stretching frequencies as a function of the metal ion.
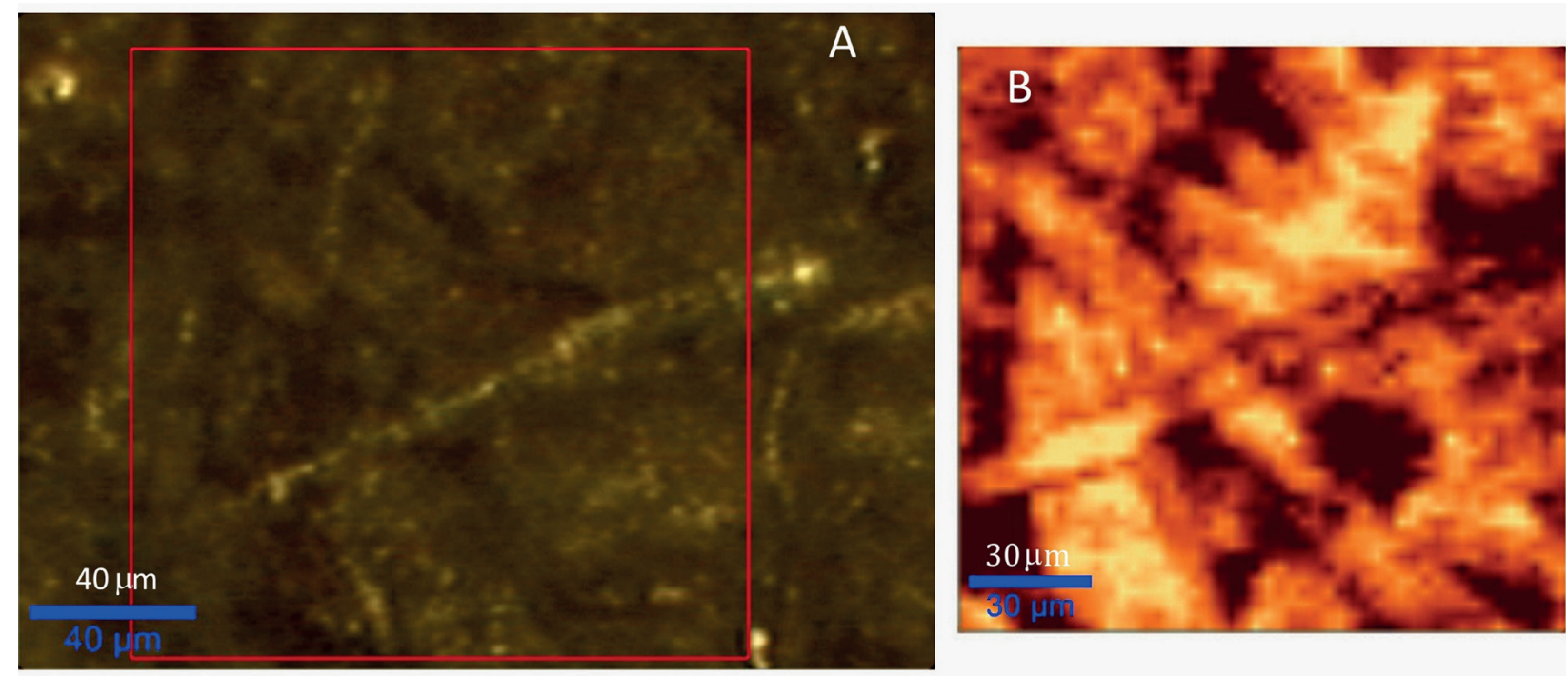

Figure 9 - (a) Optical microscopy image of the $\mathrm{Ni}_{3}\left[\mathrm{Fe}(\mathrm{CN})_{5}(\text { pyCN })\right]_{2}$ complex on the cellulose fibers in the spot test analysis, (b) hyperspectral image generated by confocal Raman spectroscopy, showing the distribution of the complex on the fibers. 
produced by $\mathrm{Zn}^{2+}$ was really surprising, providing a very useful test for this element, since most zinc complexes do not display electronic bands in the visible. The use of ring oven techniques in association with fiber optics electronic spectroscopy and confocal Raman techniques allowed to enhance the sensitivity by more than three orders of magnitude. The proposed tests expanded the classical Prussian blue test for iron(III) ions to the whole series of transition metal ions, and represents an important contribution to the Feigl's spot tests in chemistry and forensic analysis .

\section{ACKNOWLEDGMENTS}

The financial support from Fundação de Amparo à Pesquisa do Estado de São Paulo (FAPESP 2013/24725-4) and Conselho Nacional de Desenvolvimento Científico e Tecnológico (CNPq 405301/2013-8) is gratefully acknowledged.

\section{AUTHOR CONTRIBUTIONS}

Jorge S. Shinohara performed the final spot tests, Raman spectra and microscopy, Daniel Grasseschi contributed to the Confocal Raman microscopy, Sabrina N. Almeida started the initial tests and spectrophotometric assays, Henrique E. Toma was involved in all the steps of this work.

\section{REFERENCES}

CORTEZ J AND PASQUINI C 2013. Ring-Oven Based Preconcentration Technique for Microanalysis: Simultaneous Determination of $\mathrm{Na}, \mathrm{Fe}$, and $\mathrm{Cu}$ in Fuel Ethanol by Laser Induced Breakdown Spectroscopy. Anal Chem 85: 1547-1554.

CREUTZ C AND TAUBE H 1973. Binuclear complexes of ruthenium ammines. J Am Chem Soc 95: 1086-1094.

DECHOJARASSRI D, ASAINA S, OMOTE S, NISHIDA K, FURUIKE T AND TAMURA H 2017. Adsorption and desorption behaviors of cesium on rayon fibers coated with chitosan immobilized with Prussian blue. Int J Bio Macromol 104: 1509-1516.

FEIGL F 1943. Spot reaction experiments. Part IV: Protective layer effects / Part V: Solvent effects. J Chem Ed 20: 298.

FEIGL F AND ANGER V 1972. Spot tests in inorganic analysis, $6^{\text {th }}$ ed., Elsevier, Amsterdam.
FORD P, RUDD DFP, GAUNDER R AND TAUBE H 1968. Synthesis and properties of pentaamminepyridinerutheniu $\mathrm{m}(\mathrm{II})$ and related complexes of aromatic N-heterocycles. J Am Chem Soc 90: 1187-1193.

GREEEN JHS AND HARRISON DJ 1977. Vibrational spectra of cyano-pyridines, formyl-pyridines and halogenopyridines. Spectrochimica Acta Part A: Mol and Biomol Spectr 33: 75-79.

GRIFFITH WP AND TURNER GT 1970. Raman spectra and vibrational assignments of hexacyano-complexes. J Chem Soc - A - Inorg Phys Theor 858-864.

HUILA MFG, LUKIN N, PARUSSULO ALA, OLIVEIRA PV, KYOHARA PK, ARAKI K AND TOMA HE 2012. Unraveling the mysterious role of palladium in Feigl bis(dimethylglyoximate)nickel(II) spot tests by means of confocal Raman microscopy. Anal Chem 84: 3067-3069

LUDI A, GUDEL HU AND HUGI R 1969. Structure of Prussian Blue. Chimia 23: 194-199.

PARAJULI D ET AL. 2016. Application of Prussian blue nanoparticles for the radioactive Cs decontamination in Fukushima region. J Env Radio 151: 233-237.

RIYAZUDDIN P 1994. A Simple Ring Oven for Microanalysis. J Chem Ed 71: 606-609.

ROBIN MB 1961. The color and electronic configurations of Prussian blue. Spectrochim Acta 17: 1095.

ROBIN MB AND DAY P 1967. Mixed Valence-Chemistry A Survey and Classification. Adv Inorg Chem Radiochem 10: 247-422.

TOMA HE 1976. Intervalence-electron transfer spectra of several iron(III) and copper(II) pentacyanoferrate(II) complexes. J Inorg Nuclear Chem 38: 431-434.

TOMA HE, BATISTA AA AND GRAY HB 1982. Pentacyanoferrate(II) complexes of aminoacids. J Am Chem Soc 104: 7509-7515.

TOMA HE, CARTER JM AND SANTOS PS 1987. Synthesis, electronic spectdra and resonance Raman studies of a new series of cyanoiron pigments. J Chem Res - M: 226-238.

TOMA HE AND CREUTZ C 1977. Pentacyanoferrate(II) complexes - evaluation of their formal potentials and mechanism of quenching of (2,2'-bipyridine) Ruthenium(II) luminescence. Inorg Chem 16: 545-550.

TOMA HE AND MALIN JM 1973. Properties and reactivity of some pentacyanoferrate(II) complexoes of aromatic N-heterocycles. Inorg Chem 12: 1039-1045.

TOMA HE, MALIN JM AND GIESBRECHT E 1973. Ion pentacyano (dimethylsulfoxide)ferrate(II) - Synthesis, characterization and substitution kinetics in aqueous solution. Inorg Chem 12: 2084-2089.

TOMA HE AND TAKASUGI MS.1989. Preferential solvation effects in the electochemistry and charge-transfer spectra of cyanoiron(II) complexes. J Sol Chem 18: 941-945.

TOMA HE AND TAKASUGI MS 1983. Spectroscopic Studies of Preferential and Asymmetric Solvation in Substituted Cyanoiron(II) Complexes. J Sol Chem 12: 547-561. 